\title{
A ciranda da inclusão: promovendo o desenvolvimento e a interação em um grupo de jardim de infância de que faz parte uma criança com autismo
}

\author{
Isabel Rodrigues Sanches* \\ Ruthe Bezerra Falcão ${ }^{* *}$
}

Resumo

Este artigo resulta de um trabalho de projeto que utilizou uma metodologia qualitativa, numa abordagem de investigação-ação. Teve como objetivo promover uma educação inclusiva, apostando no desenvolvimento e na interação de todas as crianças, num grupo de jardim de infância, e na superação das dificuldades de uma criança com diagnóstico de autismo. Começou-se com uma fundamentação teórica sobre a educação inclusiva (SANCHES, 2005, 2012; SANCHES; TEODORO, 2006; HEWITT, 2010; LEITÃO, 2010; RODRIGUES, 2006; FONSECA, 2004), a conceptualização do autismo e respetivos métodos de intervenção (LIMA, 2012; TOLEZANI, 2010; MARQUES, 2000; PIACENTINI, 2009). Suportada pela recolha e análise dos dados da entrevista, observação e sociometria, fez-se a caraterização da situação inicial e a planificação, desenvolvimento e avaliação do plano de ação. Promovendo a interação diária com o grupo, esta criança desenvolveu as suas capacidades, por contraposição a um atendimento individual que se tinha revelado insuficiente. $\mathrm{O}$ uso sistemático de estratégias de intervenção promotoras de inclusão permitiu o desenvolvimento e a socialização de todos os alunos.

Palavras-chave: Autismo. Educação inclusiva. Estratégias de intervenção. Investigação-ação. Jardim de infância.

Doutora em Ciências da Educação pela Universidade Lumière (Lyon 2). Professora Associada na Universidade Lusófona de Humanidades e Tecnologias. Coordenadora do mestrado em Educação Especial. Investigadora integrada do Centro de Estudos Interdisciplinares em Educação e Desenvolvimento (CeiED). E-mail: isabelrsanches@gmail.com

** Mestre em Ciências da Educação - Educação Especial: Domínio Cognitivo e Motor. Doutoranda em Educação na Universidade Lusófona de Humanidades e Tecnologias. E-mail: ruthefalcao@sapo.pt 


\section{Introdução}

Desde a infância e durante toda nossa vida somos confrontados com a urgência de comunicarmos. Todavia, para alguns indivíduos, essa necessidade embate na limitação, na dificuldade ou mesmo na impossibilidade de a realizar, devido a um número variado de causas possíveis. Assim, diante desta realidade foi desenvolvido um trabalho de projeto no âmbito de Mestrado em Ciências de Educação Especial: domínio cognitivo e motor, que incidiu sobre um grupo constituído por vinte crianças com idades compreendidas entre os quatro e seis anos e que teve um enfoque numa criança com o diagnóstico de autismo, a frequentar o Jardim de Infância da rede pública dos arredores de Lisboa, Portugal, ao abrigo do Dec. Lei 3/2008, de 7 de janeiro.

Este artigo pretende documentar como se investigou, se planificou e como foram desenvolvidas estratégias de intervenção e de avaliação, para promover aprendizagens no grupo de crianças e também a inclusão de uma criança com diagnóstico de autismo, nesse mesmo grupo, uma vez que pais e educadora estavam preocupados porque a criança se isolava do seu grupo e não estava a desenvolver as suas capacidades.

\section{Contextualização teórica}

\section{A educação inclusiva}

A diversidade em sala de aula é inevitável e simultaneamente indispensável, porque não existe uma sala de aula única e a cada ano conhecem-se alunos, com histórias de vida, realidades e problemas diferentes. Diante desta realidade, a Conferência Mundial sobre Necessidades Educativas Especiais (NEE), representando noventa e dois países e vinte e cinco organizações internacionais, reunidos em Espanha, nos dias 7 a 10 de junho de 1994 em Salamanca, constituiu um avanço significativo, ao proclamar que todos os alunos devem:

aprender juntos, sempre que possível, independentemente das dificuldades e das diferenças que apresentam; das suas condições físicas, sociais, linguísticas ou outras [...] pelo que será dever de todos os governos adotarem em suas leis e políticas o princípio da educação inclusiva, matriculando todas as crianças nas escolas comuns, a menos que haja razões de força maior para não fazê-lo, e investir maior esforço em estratégias, de identificação e intervenção precoce, bem como em aspetos profissionais da educação inclusiva (UNESCO, 1994). 
O convívio escolar apresenta à criança os primeiros laços e interesses do grupo social, dando início à valorização do ser humano, seja ele portador de necessidades educativas especiais ou não. Neste sentido, a educação escolar tem o papel essencial de proporcionar às crianças sem exceção uma educação inclusiva, ou seja, segundo Leitão:

proporcionar a todos e cada um, o acesso às melhores condições de vida e de aprendizagem possíveis. Não apenas alguns, mas todos os alunos, necessitam e devem beneficiar da aceitação, ajuda e solidariedade, dos seus pares, num clima onde ser diferente é um valor (2010, p. 21).

Rodrigues (2006) refere ser indispensável entender o conceito de educação inclusiva, para se compreender a diferença entre integração e inclusão, uma vez que, na integração escolar o aluno é quem procura adaptar-se às condições que a escola oferece e na educação inclusiva não só o aluno tem que se adaptar como a escola tem de criar as condições necessárias ao seu acesso, permanência e sucesso. Assim, a escola, além de combater a exclusão, a segregação e a discriminação, ela está em contínuo processo de mudança a fim de melhor atender às necessidades de cada aluno, sejam crianças com NEE ou não, "de forma a proporcionar a todos as melhores condições de aprendizagem, sucesso e participação, na base das circunstâncias específicas de cada um" (LEITÃO, 2010, p. 1). Considerando a importância da diversidade para a aprendizagem dos alunos com NEE ou não, sabemos que são muitas as dificuldades encontradas para que haja uma equidade nos direitos e deveres de todos os alunos. Diante desta problemática, Sanches refere:

A educação inclusiva é o grande desafio de todos os que trabalham em educação. No mundo do individualismo e da competição individual, sempre frenética e usando, por vezes, estratégias pouco éticas para si e para os outros, é muito difícil pensar e falar numa sociedade mais humana (2005, p. 140).

De acordo com a mesma autora, “[...] aceder a uma educação inclusiva é procurar uma cidadania plena, no que ela comporta de direito e responsabilidade em estar com outros e com eles colaborar e aprender, num processo ativo de implicação e de tomada de decisões" (2011, p. 137), uma vez que, a educação inclusiva nos ajuda a compreender que neste processo as pessoas se apoiam mutuamente, nas suas necessidades específicas, sejam alunos ou profissionais, superando obstáculos que impedem o avanço, no sentido de garantir um ensino de qualidade. O futuro da educação inclusiva depende de projetos verdadeiramente comprometidos em transformar a escola, adequando-a aos novos tempos, novos métodos e novos objetivos (SANCHES, 2012). Fonseca entende que para implementar uma educação inclusiva ela "envolve de certa forma uma experiência de inovação, uma atitude experimental e uma avaliação qualitativa permanente" (2004, p. 59). Para Sanches, 
[...] a mudança geradora de uma educação inclusiva é um dos grandes desafios da educação de hoje porque imputa à escola a responsabilidade de deixar de excluir para incluir e de educar a diversidade dos seus públicos, numa perspetiva de sucesso de todos e de cada um, independentemente da sua cor, raça, cultura, religião, deficiência mental, psicológica ou física (2005, p. 128).

Se, como diz Hewitt, “[...] é consensualmente considerado que os ambientes educacionais regulares oferecem às crianças com Perturbações do Espectro do Autismo (PEA), uma igualdade de oportunidades, e uma melhor preparação para a vida" (2010, p. 5), os ambientes regulares inclusivos são, por ora, os mais adequados ao seu desenvolvimento. Para isto, é fundamental que professores do ensino regular e de educação especial, estejam preparados para, em sintonia, combater as dificuldades encontradas por estas crianças, nomeadamente, na comunicação, socialização e autonomia, pois são vertentes críticas da aprendizagem, que requerem a utilização de métodos de intervenção e práticas para uma educação inclusiva, tais como: o ensino cooperativo, onde os professores em conjunto dentro de sala de aula criam estratégias de instrução complementar, suportando novas atividades de aprendizagem, desenvolvendo práticas e recursos no seio da sala de aula (BAUWENS; HOURCADE; FRIEND, 1989).

Referenciando Freire, é importante que se "respeite o diferente, seus sonhos, suas ideias, suas opções, seus gostos, que não os negue só porque é diferente" (2000 apud GADOTTI, 2007, p. 24). E, apesar de todas as contrariedades e dificuldades inerentes ao respeito pelo "diferente" é possível marcar a diferença e combater a segregação social.

A formação de professores para uma educação inclusiva

Desde sempre, são muitas as responsabilidades do educador para com os seus alunos, pelo que, se os docentes não estiverem preparados para trabalhar com a diversidade, a inclusão das crianças com NEE no cotidiano escolar pode desencadear formas de estar, mais ou menos (in)conscientes, pautadas pelo desrespeito dos direitos do aluno, na sua qualidade de ser humano. Nesta perspetiva, sabe-se o quanto é importante para os alunos uma formação adequada dos professores, para os ajudar a ultrapassar as suas limitações e usufruir de forma enriquecedora de todo o contributo que a vivência sócio escolar pode proporcionar. A formação de professores é imprescindível na gestão da heterogeneidade e na inclusão dos alunos com NEE. Na perspetiva de Silva, "[...] na educação inclusiva, a formação de professores é um dos fatores fundamentais à sua implementação" (2009, p. 135). É importante que os professores acompanhem as exigências do sistema educativo tanto nas diferenças culturais quanto na educação inclusiva. 
Freire refere que "não há ensino sem pesquisa e pesquisa sem ensino" (1996, p. 29), daí que não será possível falar de uma educação inclusiva sem discutir a formação do professor, numa perspetiva de professor investigador, atento ao contexto em que se insere e reflexivo em relação às suas práticas. Ele tem um papel fundamental na educação, uma vez que é o mediador de toda essa mudança que estamos vivendo e por que ansiamos, no contexto escolar. Silva acrescenta:

[...] a inclusão não depende, apenas, da formação de professores, mas sem formação que contribua para atenuar receios e mitos socialmente construídos e dê segurança relativamente a práticas que necessariamente têm de ser implementadas, dificilmente teremos uma escola para todos na sua verdadeira aceção, isto é, uma escola que responda aos alunos de acordo com as potencialidades e as capacidades de cada um (2009, p. 151).

De acordo com o que refere Morgado, “[...] qualquer mudança ou melhoria que se pretenda concretizar a nível educativo implica, obrigatoriamente, um maior envolvimento e uma outra postura dos professores mas, também, uma outra atitude da própria sociedade" (2006, p. 99). Segundo o autor, o professor não detém autonomia na resolução dos problemas escolares, uma vez que estes "resultam da confluência e intersecção de distintos fatores a diferentes níveis" (2006, p. 100). Para isso, é fundamental a existência de uma formação adequada porque é dessa forma "que se abandona a tradicional cultura de reprodução, que tão profundamente tem marcado a vida das escolas, e se caminhe no sentido de alterar todo este quadro, construindo uma verdadeira cultura de recriação" (MORGADO, 2006, p. 106).

De acordo com Freire, "é pensando criticamente a prática de hoje ou de ontem que se pode melhorar a próxima prática” (1996, p. 39). Uma reflexão crítica sobre a teoria e prática reflete uma mudança no currículo escolar, uma vez que "não é só o currículo que é construído, mas ele também nos constrói” (SILVA, 1995 apud PAVAN, 2010, p. 132). Contudo, sabe-se que a tarefa do professor na educação não é apenas ser o transmissor dos problemas de sala de aula, mas de participar, propor soluções a agir em conformidade com a sua realidade escolar. Quando os educadores estão preparados para proporcionar uma aprendizagem que valorize a diversidade em sala de aula, este poderá ser um ponto de partida para erradicar o preconceito e contribuir para um futuro mais justo para a humanidade. A diversidade será então compreendida como uma oportunidade para se unirem forças através de suas características específicas, em prol da evolução do ser humano onde "cabe aos professores a difícil tarefa de ajudar a construir o mundo" (GUILHERME, 2009, p. 49).

Com os avanços tecnológicos, a globalização, entre outros fatores, surgiu a preocupação em promover uma educação que dê resposta a toda essa transformação em que vivemos atualmente. Porém salienta-se que toda essa transformação a nível educativo deve ter a colaboração não só dos responsáveis pelas decisões exter- 
nas da educação, mas também do conjunto de professores, pais e toda a sociedade. Neste sentido, a inclusão envolve sérios desafios e mudanças frente à formação inicial e contínua de professores, pois o currículo escolar e suas adaptações carecem de uma adequação tendo em conta a heterogeneidade dos alunos, permitindo a igualdade de oportunidades educacionais.

Diante disto, é importante refletir sobre o papel do professor na educação, para não ser ele sempre, o responsável pelo fracasso escolar, "quebrar o isolamento tradicional dos professores, partilhar experiências e saberes, encontrar novas formas de colaboração entre profissionais, partilhar responsabilidade, etc.., é algo que, para além dos desafios, riscos e incertezas que envolve, poderá revelar-se profundamente compensador e gratificante" (LEITÃO, 2010, p. 197). Portanto, a inclusão permite uma evolução positiva, uma vez que viabiliza que as pessoas se relacionem e se respeitem.

\section{Conceito e metodologias de intervenção nas perturbações do Espectro do Autismo (PEA)}

O termo autismo deriva da palavra grega autos (próprio) e traduz a ideia de "estar mergulhado em si". Foi descrita pela primeira vez no ano de 1943, pelo psiquiatra norte-americano Leo Kanner. Muitas definições foram surgindo, adequando a própria designação, passando de distúrbio a perturbação, mostrando como é difícil a sua caraterização e etiologia. Selecionou-se a de Tamanaha, Perissinoto e Chiari:

Distúrbio Autístico do Contato Afetivo, com características comportamentais bastante específicas, tais como: perturbação das relações afetivas com o meio, solidão extrema, inabilidade no uso da linguagem para comunicação, presença de potencialidades cognitivas, aspeto físico aparentemente, normal, comportamentos ritualísticos, início precoce e incidência predominante no sexo masculino (2008, p. 296).

Kanner (1943) continua a ser dos estudiosos mais citados quando se fala desta perturbação. É o caso de Lima (2012) que, citando este autor, aponta as características comportamentais do indivíduo com diagnóstico de autismo:

- incapacidade de relacionamento com os outros (não mantém contato visual com outras pessoas);

- falha na comunicação verbal e ecolalia (repetição de palavras ou frases) alguns conseguem comunicar através da fala, outros limitam-se a repetir;

- excitação fácil e apego excessivos a determinados objetos;

- focalização excessiva em detalhes - percebem rapidamente quando os objetos do seu ambiente foram mudados; 
- distratibilidade - para os autistas é difícil prestar atenção no que os seus professores querem, porque estão concentrados em sensações que para eles são mais interessantes;

- dificuldade em organizar e sequenciar - porque a capacidade de organizar requer a integração de vários elementos para atingir um objetivo predeterminado;

- ansiedade excessiva - as pessoas com diagnóstico de autismo possuem uma acentuada hiperatividade física, muitas vezes são agressivos e destrutivos;

- forte impulsividade - pessoas com diagnóstico de autismo são frequentemente persistentes em buscar coisas que eles desejem, não importando que estas sejam objetos preferidos (estes comportamentos podem ser muito difíceis para professores e pais, direcionar e canalizar estes comportamentos é o grande desafio).

Como incidência, apontam-se os índices mais aceites e divulgados, variando de 2 a 5 casos de diagnóstico para 10.000. O predomínio abrange, principalmente, o sexo masculino, numa proporção de quatro homens para uma mulher (TAMANAHA; PERISSINOTO; CHIARI, 2008).

Para a educação de alunos com PEA, um dos métodos de ensino utilizado é o método "TEACCH" (Treatment and Education of Autistic and related Communication hadicapped Children) que significa tratamento e educação para crianças autistas e com distúrbios da comunicação. $O$ seu objetivo principal é ajudar a criança com PEA a crescer e a melhorar as suas capacidades de modo a atingir o máximo de autonomia ao longo da vida. O método TEACCH utiliza uma avaliação que se baseia nas áreas fortes e fracas de cada indivíduo, chamada Perfil Psicoeducacional Revisado (PEP-R), tornando possível um programa adaptado a diferentes níveis de funcionamento da criança com diagnóstico de autismo.

Segundo Marques, o método TEACCH é "um modelo de intervenção especificamente concebido para ser desenvolvido com crianças com perturbações do espectro do autismo" (2000, p. 91). O programa foi idealizado e desenvolvido pelo Dr. Eric Schoppler na década de 1970, no Departamento de Psiquiatria da Faculdade de Medicina da Universidade da Carolina do Norte nos Estados Unidos, é atualmente aplicado em várias partes do mundo. Segundo Lima,

[...] a metodologia TEACCH consiste num programa estruturado que fornece informações claras e objetivas sobre como se deve avaliar, delinear e implementar uma intervenção elaborada para uma pessoa com diagnóstico de autismo e envolve desde o início os pais e todos aqueles que intervêm no processo psicoeducacional. Trata-se de uma metodologia de trabalho que baseia as suas estratégias nas áreas fortes da criança com PEA que são o processamento visual memorização de rotinas e interesses pessoais (2012, p. 43). 
Existem outros métodos de intervenção no autismo, o método Applied Behavior Analysis (ABA) - que consiste numa análise aplicada ao comportamento, de forma a ensinar à criança capacidades que ela não possui, através da sua introdução por etapas. Este método é aplicado através dum esquema individual apresentado por indicação ou instrução. Complementarmente, se necessário, é oferecido um apoio físico, mas o quanto antes ele for retirado melhor para que a criança não se torne dependente. É fundamental que a aprendizagem seja agradável para a criança e que ela identifique os diferentes estímulos, pois a repetição é um fator importante nesta abordagem (LIMA, 2012). O método DIR/Floortime também é outro método que teve a sua origem nos Estados Unidos com o psiquiatra Stanley Greenspan e Serena Wielder. A sigla DIR significa Desenvolvimento Diferencial Individual e Relacional e o Floortime, é explicado por utilizar uma técnica em que os adultos trabalham com crianças com diagnóstico de autismo no chão, a fim de com ela interagirem olho no olho. Este método vem sendo utilizado desde há uma década e baseia-se na premissa de que a criança pode melhorar ao construir um grande círculo de interesses e de interação com um adulto independentemente do seu estágio atual de desenvolvimento. O Floortime não separa ou foca as diferentes habilidades da fala, motoras ou cognitivas, mas guia essas capacidades, enfatizando o desenvolvimento emocional (PIACENTINI, 2009). Também faz parte dos métodos de intervenção o Son Rise que foi criado na década de 1970, por Barry Neil Kaufman e Samanhria Kaufman, após lhes terem dito que o seu filho Ron tinha um autismo severo incurável com um QI abaixo de 40. Na sequência do diagnóstico os autores/pais foram aconselhados a internar o seu filho numa instituição devido à sua "condição", que não apresentava boas perspetivas futuras. A partir daí o casal de professores desenvolveu um programa para ser aplicado em casa, centrado na criança, com uma abordagem muito relacional e com grande ênfase na iniciativa da mesma, onde a relação interpessoal é valorizada (TOLEZANI, 2010).

Torna-se essencial uma formação específica e contínua do professor para o uso correto dessas técnicas, uma vez que o aluno deve ser devidamente auxiliado e acompanhado para fazer aprendizagens.

Em Portugal, em 7 de Janeiro de 2008 foi publicado o Decreto-Lei 3/2008 que teve como objetivo responder às necessidades de inclusão das crianças e jovens com necessidades educativas especiais - NEE no contexto escolar. No Artigo 25..$^{\circ} n^{\circ} 1$ - o decreto estabelece, entre outras medidas educativas, unidades de ensino estruturado para a educação de alunos com perturbações do espectro do autismo, para dar uma resposta a esta comunidade educativa. O seu objetivo principal é ajudar a criança com PEA a crescer e a melhorar as suas capacidades de modo a atingir o máximo de autonomia ao longo da vida. Este mesmo Artigo estabelece a aplicação 
e desenvolvimento de metodologias de intervenção, para facilitar os processos de ensino e aprendizagem dos alunos com PEA, contribuindo para a autonomia e a adaptação no contexto escolar, uma vez que a intervenção precoce e programas especializados para crianças com diagnóstico de autismo podem contribuir para resultados significativos.

\section{Contextualização metodológica}

O nosso trabalho utilizou uma metodologia qualitativa, na abordagem investigação-ação, com o objetivo de produzir mudanças, através de uma resposta a problemas concretos, como diz Esteves: "formular questões a estudar, elaborar os objetivos a prosseguir e as metodologias para os abordar e monitorizar, definir formatos para avaliar os resultados" (2008, p. 11), possibilitando-nos agir e investigar a ação, transformando-a. Uma vez que o nosso trabalho se desenrola no contexto educativo, a nossa opção teve em consideração o que nos dizem Marques e Sarmento: "a investigação-ação é promotora de mudanças nas formas de colaboração interpessoal, é motor de cidadania de cada ator social, na reconstrução de novas formas de solidariedade social e educativa" (2007, p. 101).

Diante disto, para o seu desenvolvimento inicial, buscou-se caracterizar o grupo de 20 (vinte) alunos com idades compreendidas entre os 4 (quatro) e 6 (seis) anos de idade, dos quais 12 doze são meninas e 8 oito são meninos, entre eles, uma criança com o diagnóstico de autismo. As técnicas utilizadas para investigar e caracterizar o grupo foram: as observações naturalistas (inicial e final), entrevistas com as educadoras (inicial e final), testes sociométricos ${ }^{1}$ no grupo (inicial e final), pesquisa documental do "Eduardo" (informação clínica psiquiátrica e psicológica, ficha de referenciação, relatório técnico pedagógico, classificação internacional de funcionamento, incapacidade e saúde, programa educativo individual e o relatório circunstanciado de avaliação final da criança) e o plano anual de atividades do jardim de infância (JI).

A informação recolhida foi analisada, com rigor metodológico, utilizando os modelos de referência, de acordo com as respetivas técnicas de recolha de dados. Assim, para os testes sociométricos, a fim de encontrar a interação das crianças no grupo, no início e no final da intervenção, foi feito um estudo quantitativo; para as entrevistas e pesquisa documental, para caraterizar o grupo e o aluno, no início, bem como para avaliar a intervenção no final, foi utilizada a análise de conteúdo, modelo Bardin (1977), cotejado por leituras mais recentes, como Estrela (1984) e Guerra (2006). 
A partir da análise da problemática foi construído um plano de ação, buscando responder a questões suscitadas por um grupo de crianças no Jardim de Infância, onde se encontrava uma criança com o diagnóstico de autismo.

De acordo com os dados adquiridos através da análise dos dados recolhidos pelo teste sociométrico, pela observação naturalista e pelas entrevistas realizadas à educadora titular e à professora de educação especial, o grupo de crianças do Jardim de Infância apresentava dificuldades de aprendizagens e a exclusão de uma criança com diagnóstico de autismo nas atividades desenvolvidas em sala de aula, sendo a mesma retirada do grupo para realizar as suas atividades. Diante desta realidade, o projeto teve como ponto de partida responder à seguinte questão: Como promover o desenvolvimento e a participação de todos os alunos, num grupo de Jardim de Infância, e incluir uma criança com diagnóstico de autismo?

Neste sentido, o nosso trabalho de investigação-ação teve como objetivo promover a participação, socialização e aprendizagens de todas as crianças de um grupo de Jardim de Infância, em que se encontrava uma criança com autismo. Assim, para atingir o objetivo enunciado, definimos e propusemo-nos desencadear os seguintes procedimentos:

- verificar como se processavam as interações entre a criança com autismo e o seu grupo;

- caracterizar como se processavam as interações entre a educadora titular e a professora de educação especial;

- caracterizar o conhecimento e a utilização dos métodos e estratégias de intervenção no autismo, entre as educadoras do grupo;

- desenvolver estratégias de intervenção educativas para promover a participação, socialização e aprendizagens do grupo no JI;

- propor uma continuidade pedagógica e parceria nos trabalhos e objetivos por parte da educadora titular e a professora de educação especial;

- interagir com a família da criança com autismo no sentido de dar continuidade ao trabalho desenvolvido na escola.

A avaliação dos objetivos propostos ocorreu sistematicamente, para poder verificar se estavam sendo alcançados ou não e, em conformidade, proceder às possíveis mudanças. Segundo Leite, Malpique e Santos,

o verdadeiro método pedagógico consiste primeiro em tornarmo-nos inteligentemente atentos às aptidões, às necessidades, às experiencias vivenciadas pelos educandos e, em segundo lugar, em desenvolver estas sugestões de base de tal forma que elas se transformem num plano ou num projeto que, por sua vez, se organize num todo assumido pelo grupo (1990, p. 17). 


\section{Plano de ação}

A planificação da intervenção foi preparada após o levantamento das competências do grupo, resultante da recolha e da análise dos dados em conformidade com os conteúdos das Orientações Curriculares, o Plano Anual de Atividades do Jardim de Infância; o Programa Educativo Individual - PEI e a Classificação Internacional de Funcionamento, Incapacidade e Saúde - CIF do Eduardo. As planificações foram realizadas em conjunto entre a autora do projeto, a educadora titular e a professora de educação especial do grupo. Diante da problemática do grupo e do "Eduardo", verificou-se a necessidade das atividades serem direcionadas para todas as crianças do grupo, uma vez que a faixa etária, entre os 4 (quatro) e 6 (seis) anos de idade, facilitava o planeamento da intervenção de uma forma que todos pudessem desenvolver as suas competências. O projeto assentou no trabalho com todo o grupo, criando situações de aprendizagem, para desenvolver a socialização, autonomia, linguagem, cognição e desenvolvimento motor, trabalhando sempre a dinâmica de todo o grupo. Neste sentido, foi realizada uma planificação global da intervenção, depois desdobrada em atividades mensais. Veja-se, a título de exemplo, a programação para o mês de maio no Quadro 1.

Quadro 1 - Planificação global mês de maio

\begin{tabular}{|c|c|c|}
\hline $\begin{array}{c}\text { Semana de } \\
\text { ilntervenção }\end{array}$ & Objetivos & Atividades \\
\hline $\begin{array}{l}\text { 8a Semana } \\
03 / 05 / 12\end{array}$ & $\begin{array}{l}\text { - Identificar os números naturais } \\
\text { utilizando os dados. }\end{array}$ & $\begin{array}{l}\text { - Jogar os dados } \\
\text { - Preencher no quadro a carapaça da tartaruga } \\
\text { com os números correspondentes (Figura 1). }\end{array}$ \\
\hline $\begin{array}{l}\text { 9a Semana } \\
10 / 05 / 12\end{array}$ & $\begin{array}{l}\text { - Associar a palavra à figura da } \\
\text { imagem correspondente. }\end{array}$ & $\begin{array}{l}\text { - Colar no cartão as palavras correspondentes a } \\
\text { cada figura de imagem (Figura 2). }\end{array}$ \\
\hline $\begin{array}{l}\text { 10a Semana } \\
17 / 05 / 12\end{array}$ & $\begin{array}{l}\text { - Praticar a pintura com lápis de } \\
\text { cor para desenvolver a coorde- } \\
\text { nação motora. }\end{array}$ & $\begin{array}{l}\text { - Pintar as áreas marcadas com um pontinho (.) } \\
\text { para descobrir o desenho escondido. Em segui- } \\
\text { da, completar o desenho do leão (Figura 3). }\end{array}$ \\
\hline $\begin{array}{l}\text { 11a Semana } \\
\text { 24/05/12 }\end{array}$ & $\begin{array}{l}\text { - Identificar o próprio nome atra- } \\
\text { vés do número correspondente } \\
\text { inscrito nos balões. }\end{array}$ & $\begin{array}{l}\text { - Reconhecer os números nos balões } \\
\text { - Retirar o papel de dentro do balão com o pró- } \\
\text { prio nome escrito } \\
\text { - Escrever o próprio nome no papel (Figura 4). }\end{array}$ \\
\hline $\begin{array}{l}12^{\text {a }} \text { Semana } \\
31 / 05 / 12\end{array}$ & $\begin{array}{l}\text { - Relacionar os números naturais } \\
\text { com as respetivas quantidades. }\end{array}$ & $\begin{array}{l}\text { - Passar por cima dos números com o lápis e uni- } \\
\text {-los à respetiva quantidade de nuvens (Figura 5). }\end{array}$ \\
\hline
\end{tabular}

Fonte: elaboração dos autores. 
Quadro 2 - Figuras de atividades realizadas no mês de maio

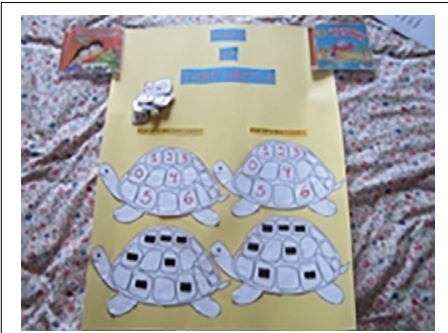

Figura 1 - Jogar os dados; Preencher no quadro a carapaça da tartaruga com os números correspondentes.

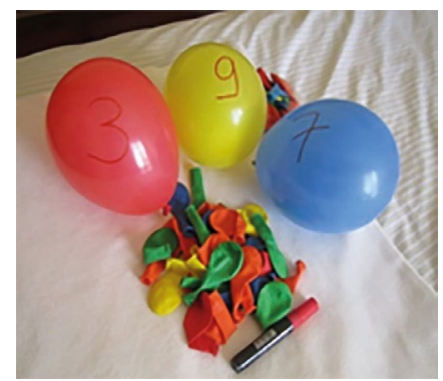

Figura 4 - Atividade para encontrar o nome dentro do balão; promover a Comunicação e Cognição).

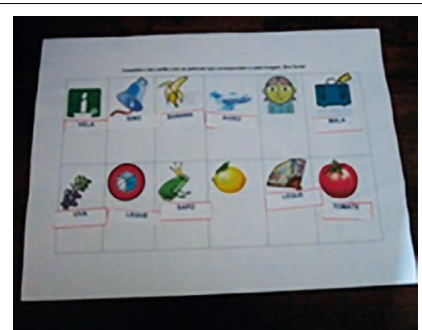

Figura 2 - Completar o cartão com palavras que corresponde a cada imagem.

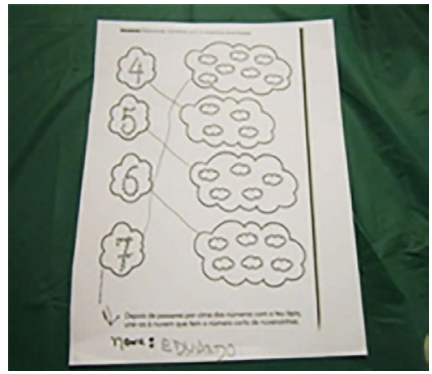

Figura 5 - Passar por cima dos números com o lápis e uni-los à respetiva quantidade.

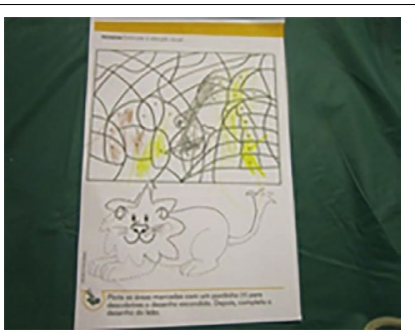

Figura 3 - Pintar as áreas marcadas com um pontinho (.) para descobrir o desenho escondido. Em seguida completar o desenho do leão.

Fonte: elaboração dos autores.

No final de cada mês, a equipa pedagógica (autora do projeto, educadora do grupo e professora de Educação especial) reunia, para avaliar e refletir sobre o resultado do trabalho desenvolvido, centrando-se nos desempenhos das crianças (Quadro 3) e nos registos das observações feitas no decorrer das atividades, donde saíam as propostas de atividades para o mês seguinte, adequando a planificação global. 
Quadro 3 - Avaliação das atividades realizadas pelo grupo no mês de maio

\begin{tabular}{|c|c|c|c|c|c|c|c|c|c|c|c|c|c|c|c|c|c|c|c|c|}
\hline \multirow{2}{*}{$\begin{array}{l}\text { Nome das Crianças } \\
\text { Objetivos } \\
\text { Mês de Maio }\end{array}$} & \multicolumn{12}{|c|}{ Sexo feminino } & \multicolumn{8}{|c|}{ Sexo masculino } \\
\hline & $\dot{<}$ & $\ddot{U}$ & $\dot{u}$ & 《் & j & $\Sigma$ & $\vec{\Sigma}$ & 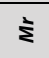 & ఏ & $n$ & ทั & $\stackrel{\infty}{\Sigma}$ & $\varangle$ & ธ் & $\sum_{0}^{\dot{0}}$ & ì & $\checkmark$ & - & $\propto$ & ¿ \\
\hline $\begin{array}{l}\text { 8a Semana - } \\
\text { Jogar os dados; } \\
\text { Preencher no quadro a } \\
\text { carapaça da tartaruga com } \\
\text { os números } \\
\text { correspondentes (Figura 8). }\end{array}$ & (;) & ;) & (-) & ๑ & - & ;:- & ;) & (2) & - & ;) & (2) & (:) & ;) & (-) & (i) & ๑) & (-) & ;) & (-) & (i) \\
\hline $\begin{array}{l}\text { 9a Semana - } \\
\text { Colar no cartão as palavras } \\
\text { correspondentes a cada } \\
\text { figura de imagem (Figura 9). }\end{array}$ & (-) & ;) & ;) & (-) & (-) & (2) & (-) & (2) & - & (-) & (-) & (-) & (2) & ;) & (2) & - & (-) & (2) & (-) & (i) \\
\hline $\begin{array}{l}10^{\text {a Semana - }} \\
\text { Pintar as áreas marcadas } \\
\text { com um pontinho (.) para } \\
\text { descobrir o desenho } \\
\text { escondido. Em seguida, } \\
\text { completar o desenho do } \\
\text { leão (Figura 10). }\end{array}$ & (i) & (2) & ;) & (2) & (2) & ;) & (-) & (i) & ๑ & (-) & (i) & (;) & (-) & ;) & (i) & - & ; & (-) & (i) & (i) \\
\hline $\begin{array}{l}\text { 11a Semana - Reconhecer } \\
\text { os números nos balões; } \\
\text { Retirar o papel de dentro } \\
\text { do balão com o próprio } \\
\text { nome escrito; } \\
\text { Escrever o próprio nome no } \\
\text { papel (Figura 11). }\end{array}$ & (i) & (i) & ;) & (;) & $\bullet$ & ๑ & (-) & (i) & $\bullet$ & (;) & (-) & ;) & ; & (-) & (i) & (2) & (-) & (i) & (i) & (-) \\
\hline $\begin{array}{l}12^{\text {a Semana - }} \\
\text { Passar por cima dos } \\
\text { números com o lápis e uni- } \\
\text { los à respetiva quantidade } \\
\text { de nuvens (Figura 12). }\end{array}$ & (i) & ;) & ;) & ;) & ๑) & ;) & ;) & (i) & $\bullet$ & (i) & ;) & ;) & ; & ;) & ๑๑ & • & ;) & (i) & (i) & (2) \\
\hline
\end{tabular}

Fonte: elaboração dos autores.

Após cada atividade semanal, era realizada uma breve avaliação e reflexão da atividade desenvolvida e trocadas impressões sobre possíveis alterações/introduções a fazer na atividade que se seguia.

\section{Resultados obtidos}

Para chegar aos resultados, analisámos primeiramente as aquisições realizadas pelas crianças nas doze semanas de intervenção, destacando a avaliação dos objetivos trabalhados, depois através da comparação dos resultados dos testes sociométricos iniciais e finais, apurámos as alterações na interação social do grupo. Finalmente, fizemos uma avaliação mais cuidada do aluno "caso", o Eduardo. 
Objetivos trabalhados

De acordo com Lima "a verdadeira aquisição de um novo conhecimento implica sempre a generalização do mesmo, demonstrando a sua flexibilidade" (2012, p. 73). Desta forma, elaborar um programa de intervenção é tão importante quanto avaliar o sucesso de cada intervenção. Para isso, a cada término de uma atividade houve a necessidade de realizar pela autora do projeto e a educadora titular, uma avaliação dos objetivos atingidos ou não pelo grupo, para que pudesse, se necessário, haver uma mudança significativa nas próximas atividades. Neste sentido, os objetivos gerais planificados em conjunto entre a autora do projeto, a educadora titular e a professora de educação especial do grupo, foram sendo adquiridos gradualmente. A título exemplificativo, a avaliação dos objetivos gerais adquiridos pelo grupo no mês de março, abril, maio e junho, durante a intervenção, encontra-se no Quadro 4.

Quadro 4 - Avaliação dos objetivos trabalhados

\begin{tabular}{|c|c|c|c|c|c|c|c|c|c|c|c|c|c|c|c|c|c|c|c|c|}
\hline Nome das & \multicolumn{12}{|c|}{ Género feminino } & \multicolumn{8}{|c|}{ Género masculino } \\
\hline $\begin{array}{l}\text { crianças } \\
\text { Avaliaçăo } \\
\text { dos } 16 \\
\text { objetivos } \\
\text { trabalhados }\end{array}$ & $\begin{array}{c}2 \\
\text { An }\end{array}$ & $\begin{array}{l}3 \\
\mathrm{CF}\end{array}$ & $\begin{array}{c}4 \\
\text { CV }\end{array}$ & $\begin{array}{l}8 \\
F\end{array}$ & $\begin{array}{c}10 \\
\mathrm{~L}\end{array}$ & $\begin{array}{c}12 \\
\text { Mad }\end{array}$ & $\begin{array}{l}13 \\
M L\end{array}$ & $\begin{array}{l}14 \\
\text { MP }\end{array}$ & $\begin{array}{l}15 \\
\text { Mar }\end{array}$ & $\begin{array}{l}18 \\
\text { Sa }\end{array}$ & $\begin{array}{l}19 \\
\mathrm{Si}\end{array}$ & $\begin{array}{c}20 \\
\text { Mar B }\end{array}$ & $\begin{array}{c}1 \\
\text { Af }\end{array}$ & $\begin{array}{c}5 \\
D P\end{array}$ & $\begin{array}{c}6 \\
\mathrm{DM}\end{array}$ & $\begin{array}{l}7 \\
E\end{array}$ & $\begin{array}{l}9 \\
\mathrm{G}\end{array}$ & $\begin{array}{c}11 \\
\mathrm{~L}\end{array}$ & $\begin{array}{l}16 \\
\text { Rob }\end{array}$ & $\begin{array}{c}17 \\
\text { Rod }\end{array}$ \\
\hline (2) Atingiu & 16 & 16 & 16 & 12 & 8 & 14 & 15 & 15 & 8 & 16 & 16 & 16 & 16 & 15 & 9 & 5 & 14 & 16 & 16 & 14 \\
\hline $\begin{array}{l}\text { Atingiu com } \\
\text { ajuda }\end{array}$ & & & & 4 & 8 & 2 & 1 & 1 & & & & & & 1 & 7 & 11 & 2 & & & 2 \\
\hline -3ão atingiu & & & & & & & & & & & & & & & & & & & & \\
\hline - Faltou & & & & & & & & & 8 & & & & & & & & & & & \\
\hline
\end{tabular}

Fonte: elaboração dos autores.

Do grupo dos 20 alunos, 9 atingiram, em pleno, todos os objetivos. A ajuda foi dada a 10, dos quais o Eduardo (E) foi o que mais ajuda obteve (obteve ajuda em 11 dos 16 trabalhados).

\section{Interação social}

Para avaliar a interação do grupo, no início e no final da intervenção, foram aplicados os testes sociométricos, uma adaptação dos testes de Nortway e Weld (1957), donde apurámos os seguintes resultados: 
Quadro 5 - Total de escolhas que cada criança obteve (antes da intervenção)

\begin{tabular}{|c|c|c|c|c|c|c|c|c|c|c|c|c|c|c|c|c|c|c|c|c|}
\hline Género & \multicolumn{12}{|c|}{ Feminino } & \multicolumn{8}{|c|}{ Masculino } \\
\hline Crianças & $\begin{array}{c}2 \\
\text { An }\end{array}$ & $\begin{array}{c}3 \\
C F\end{array}$ & $\begin{array}{c}4 \\
C V\end{array}$ & $\begin{array}{l}8 \\
\mathrm{~F}\end{array}$ & $\begin{array}{c}10 \\
\mathrm{~L}\end{array}$ & $\begin{array}{c}12 \\
\text { Mad }\end{array}$ & $\begin{array}{r}13 \\
\mathrm{ML}\end{array}$ & $\begin{array}{c}14 \\
\text { MP }\end{array}$ & $\begin{array}{c}15 \\
\text { Mar }\end{array}$ & $\begin{array}{l}18 \\
\text { Sa }\end{array}$ & $\begin{array}{l}19 \\
\mathrm{Si}\end{array}$ & $\begin{array}{c}20 \\
\text { Mar B }\end{array}$ & $\begin{array}{c}1 \\
\text { Af }\end{array}$ & $\begin{array}{c}5 \\
D P\end{array}$ & $\begin{array}{c}6 \\
D M\end{array}$ & $\begin{array}{l}7 \\
E\end{array}$ & $\begin{array}{l}9 \\
\mathrm{G}\end{array}$ & $\begin{array}{l}11 \\
\mathrm{~L}\end{array}$ & $\begin{array}{c}16 \\
\text { Rob }\end{array}$ & $\begin{array}{c}17 \\
\text { Rod }\end{array}$ \\
\hline $\begin{array}{l}\text { Total de } \\
\text { escolhas } \\
\text { obtidas }\end{array}$ & 19 & 9 & 5 & 5 & 5 & 4 & 9 & 7 & 3 & 13 & 7 & 0 & 10 & 7 & 4 & 1 & 3 & 10 & 0 & 5 \\
\hline $\begin{array}{l}\text { No de } \\
\text { indivíduos } \\
\text { por quem } \\
\text { cada um é } \\
\text { escolhido }\end{array}$ & 8 & 5 & 2 & 3 & 4 & 2 & 4 & 3 & 2 & 8 & 5 & 0 & 4 & 3 & 3 & 1 & 3 & 6 & 0 & 3 \\
\hline
\end{tabular}

Fonte: elaboração dos autores.

Quadro 6 - Total de escolhas que cada criança obteve (depois da intervenção)

\begin{tabular}{|c|c|c|c|c|c|c|c|c|c|c|c|c|c|c|c|c|c|c|c|c|}
\hline Género & \multicolumn{12}{|c|}{ Feminino } & \multicolumn{8}{|c|}{ Masculino } \\
\hline Crianças & $\begin{array}{c}2 \\
A n\end{array}$ & $\begin{array}{c}3 \\
C F\end{array}$ & $\begin{array}{c}4 \\
C V\end{array}$ & $\begin{array}{l}8 \\
F\end{array}$ & $\begin{array}{c}10 \\
\mathrm{~L}\end{array}$ & $\begin{array}{c}12 \\
\text { Mad }\end{array}$ & $\begin{array}{r}13 \\
\mathrm{ML}\end{array}$ & $\begin{array}{r}14 \\
\text { MP }\end{array}$ & $\begin{array}{r}15 \\
\mathrm{Ma}\end{array}$ & $\begin{array}{l}18 \\
\text { Sa }\end{array}$ & $\begin{array}{l}19 \\
\mathrm{Si}\end{array}$ & $\begin{array}{c}20 \\
\text { Mar B }\end{array}$ & $\begin{array}{c}1 \\
\text { Af }\end{array}$ & $\begin{array}{c}5 \\
D P\end{array}$ & $\begin{array}{c}6 \\
\text { DM }\end{array}$ & $\begin{array}{l}7 \\
\mathrm{E}\end{array}$ & $\begin{array}{l}9 \\
\mathrm{G}\end{array}$ & $\begin{array}{c}11 \\
\mathrm{~L}\end{array}$ & $\begin{array}{c}16 \\
\text { Rob }\end{array}$ & $\begin{array}{c}17 \\
\text { Rod }\end{array}$ \\
\hline $\begin{array}{l}\text { Total de } \\
\text { escolhas } \\
\text { obtidas }\end{array}$ & 10 & 5 & 0 & 4 & 9 & 10 & 8 & 6 & 0 & 19 & 12 & 15 & 6 & 1 & 2 & 13 & 5 & 4 & 0 & 6 \\
\hline $\begin{array}{l}\text { No de } \\
\text { indivíduos } \\
\text { por quem } \\
\text { cada um é } \\
\text { escolhido }\end{array}$ & 7 & 3 & 0 & 4 & 6 & 6 & 7 & 6 & 0 & 11 & 7 & 8 & 3 & 1 & 2 & 12 & 3 & 3 & 0 & 4 \\
\hline
\end{tabular}

Fonte: elaboração dos autores.

Como se pode ver nos Quadros 5 e 6, manteve-se a ausência de escolhas para Rob, sendo que CV e Mar também não obtiveram qualquer escolha. MarB passou de 0 escolhas para 15; 8 dos seus colegas escolheram-na para jogar, trabalhar e ficar perto. Também E aumentou as suas escolhas de 1 para 13 (de destacar que o projeto estava a ser feito, tendo como principal enfoque o $\mathbf{E}$ e que as crianças se apercebem do que está a ser feito à sua volta). De qualquer modo poderemos afirmar que o $\mathbf{E}$ começou a ser um elemento do grupo, deixando de ser ignorado, como acontecia no início da intervenção.

Nos registos das observações realizadas no decorrer das sessões, pode constatar-se que as crianças melhoraram no desenvolvimento das atividades em grupo, sendo mais solidários nas relações interpessoais. 


\section{Nível atual das competências do "Eduardo"}

Apesar de toda a intervenção ter sido realizada no grupo e com o grupo das crianças e da avaliação global que já foi feita em relação ao grupo, cabe destacar, um pouco mais em pormenor as aquisições de "Eduardo", tendo como referência as opiniões emitidas pelas educadoras e os registos das sessões de trabalho.

$\mathrm{Na}$ última entrevista à educadora titular do grupo, com o objetivo de avaliar a intervenção realizada, relativamente às competências adquiridas pelo Eduardo, esta referiu que o mesmo:

[...] teve um avanço a nível da capacidade de concentração e atenção, ele melhorou. Consegue executar jogos ou atividades propostas embora sempre com o acompanhamento de um adulto. $\mathrm{O}$ que até aqui não acontecia, mesmo com um adulto ao lado ele desligava. Agora já consegue manter-se na execução de um jogo ou atividade. A nível do grande grupo, no tapete, já consegue mais tempo sentado, não quer dizer que perceba uma história, mas, pelo menos, já não se levanta.

O "Eduardo" (E) adaptou-se gradualmente às atividades do Jardim de Infância, onde desenvolveu competências de interação social, consegue brincar na casinha na companhia de algum amigo e aceita muito bem as manifestações de afeto dos colegas quando o agarram. Beijos, o "Eduardo" nunca os recusa. Manifesta preferência por alguns colegas, nomeadamente, a "Carolina" pois percebemos que ele consegue estar mais tempo numa atividade se a Carolina estiver, foi nela que ele se fixou.

Segundo a última entrevista realizada à professora de educação especial, em relação ao nível da linguagem do "Eduardo", a professora referiu que:

[...] na linguagem teve algum avanço, não é? Isto mais para o $3^{\circ}$ período. Começou a dizer mais palavras. A dizer o nome dele outra vez, que tinha deixado de dizer entretanto. $\mathrm{Na}$ autonomia ele já vai à casa de banho, faz a higiene sozinho: puxa as calças e lava as mãos.

Na comunicação verbal a professora de educação especial afirmou que:

Começou a dizer mais palavras. Recomeçou a dizer o nome. Diz "xixi" para ir à casa de banho. Por vezes engana-nos, diz "xixi” só para sair. Eu acho que ele está mais curioso: ouve um som e quer ir ver quem é.

O "Eduardo" aumentou de fato, o número de vocábulos que produz, demonstrando uma maior intenção para se comunicar recorrendo ao adulto; reage quando o chamam pelo nome; compreende o que lhe foi pedido na maioria das vezes; identifica através do jogo no computador objetos e imagens. O Quadro 7 apresenta um resumo de algumas competências que o "Eduardo" adquiriu e realizou, na área da socialização, autonomia, linguagem, cognição e desenvolvimento motor, visíveis no Relatório Circunstanciado de Avaliação Final e no Projeto Educativo Individual - PEI. 
Quadro 7 - Competências atingidas pelo “Eduardo"

\begin{tabular}{|c|c|}
\hline $\begin{array}{c}\text { Área de } \\
\text { desenvolvimento }\end{array}$ & Competência \\
\hline Socialização & $\begin{array}{l}\text { - Brinca na casinha na companhia de um amigo; } \\
\text { - Aceita muito bem as manifestações de afeto dos colegas quando o } \\
\text { - Agarram e o beijam; } \\
\text { - Manta-se gradualmente às atividades do jardim de infância; } \\
\text { - Participa em todas atividades. }\end{array}$ \\
\hline Autonomia & $\begin{array}{l}\text { - Executa jogos e atividades propostas; } \\
\text { - Vai à casa de banho sozinho; } \\
\text { - Puxa as calças; } \\
\text { - Puxa o autoclismo; } \\
\text { - Lava as mãos depois de utilizar a casa de banho; } \\
\text { - Joga no lixo a caixinha do leite depois do lanche. }\end{array}$ \\
\hline Linguagem & $\begin{array}{l}\text { - Diz seu nome e alguns vocábulos; } \\
\text { - Reage quando chamam pelo seu nome; } \\
\text { - Responde ao que lhe é pedido na maioria das vezes; } \\
\text { - Identifica através do jogo no computador objetos e imagens. }\end{array}$ \\
\hline Cognição & $\begin{array}{l}\text { - Revela maior interesse pelo computador; } \\
\text { - Segue as regras do jogo no computador; } \\
\text { - Distingue algumas cores: vermelho, azul, amarela; } \\
\text { - Distingue figuras geométricas: triângulo, retângulo, círculo, quadrado; } \\
\text { - Trabalha com as Tecnologias de Informação e Comunicação - TIC; } \\
\text { - Coloca peças num tabuleiro de encaixe. }\end{array}$ \\
\hline Desenvolvimento motor & $\begin{array}{l}\text { - Manipula objetos; } \\
\text { - Maneja objetos finos; } \\
\text { - Coordena movimentos amplos; } \\
\text { - Dança e pula ao som da música; } \\
\text { - Realiza atividades de expressão corporal; } \\
\text { - Cumpre regras pré-estabelecidas. }\end{array}$ \\
\hline
\end{tabular}

Fonte: elaboração dos autores.

De acordo com o que foi estabelecido no Programa Educativo Individual do "Eduardo" e considerando as medidas educativas adotadas, estas contribuíram para o desenvolvimento das capacidades e do processo de ensino-aprendizagem deste aluno e de todo o grupo. O Relatório Circunstanciado de Avaliação Final, realizado pela professora de educação especial do "Eduardo", também foi um instrumento que nos ajudou a perceber se houve mudanças a nível de socialização do "Eduardo". Segundo a professora o "Eduardo" adaptou-se gradualmente às ativida- 
des do grupo JI conseguindo ficar mais tempo realizando as atividades com sucesso. $\mathrm{Na}$ área da linguagem/comunicação o "Eduardo", no terceiro período do ano letivo começou a dizer novamente seu nome e alguns vocábulos. Na linguagem recetiva, passou a reagir quando o chamavam compreendendo o que lhe era pedido na maior parte das vezes. $\mathrm{Na}$ área cognitiva revelou maior dificuldade necessitando do apoio constante do adulto. O "Eduardo" demonstrava maior interesse pelo computador. $\mathrm{Na}$ área motora ainda tinha o tónus muscular fraco comprometendo a realização de algumas atividades que envolvem a motricidade fina. Gostava de dançar e pular ao som da música e de atividades de expressão corporal. O "Eduardo" adaptou-se gradualmente às atividades do Jardim de Infância, desenvolveu competências de interação social, conseguindo brincar na companhia de algum amigo, aceitando bem as manifestações de afeto dos colegas quando o abraçavam.

A continuação de uma intervenção pedagógica em parceria entre as educadoras do grupo deveria manter-se, uma vez que se teve como assumido que a mesma era facilitadora e promotora de aprendizagens e da participação das crianças nas atividades.

\section{Reflexões conclusivas}

Através do plano de ação desenvolvido, em conformidade, com o que a legislação e o discurso educativo propõem em termos de inclusão de crianças com NEE, pudemos intervir e dar uma resposta ao Eduardo, proporcionando-lhe novas/outras oportunidades, através da gestão da diversidade na sala de aula, da qual decorreram os diferentes tipos de estratégias e respostas às suas necessidade educativas e do seu grupo. As atividades foram sendo construídas a partir das orientações das educadoras sem fugir da rotina diária do grupo, procurando investir em atividades colaborativas, para que todos pudessem participar, sempre "privilegiando o incentivo do grupo em vez do incentivo individual”, como diz Sanches (2005, p. 134). Algumas dificuldades foram surgindo para o desenvolvimento deste trabalho de investigação que se encontravam associadas ao facto de as educadoras não acreditarem na possibilidade de o Eduardo poder aprender; talvez por a educadora titular não estar habituada a trabalhar em conjunto com os seus pares, tendo confessado numa entrevista concedida que sentia a necessidade de um apoio, uma vez que havia uma criança com NEE no grupo. Quando começaram a surgir os primeiros resultados, quando as crianças começaram a mostrar mais motivação e quando o Eduardo cada vez mais realizava atividades junto ao grupo, fomos sentindo a importância do trabalho em equipa. Verificámos que houve a participação do "Eduardo" nas atividades planeadas, realizando-as com alegria e demonstrando 
mais aceitação por atividades que exigissem movimentos, tais como: correr, dançar, jogar no computador e interesse por instrumentos musicais. No entanto, em algumas atividades o "Eduardo" precisou de ajuda para poder cumpri-las, entretanto, ficou evidente a sua inclusão nas atividades de grupo.

De acordo com os dados obtidos antes do início da intervenção, ficou evidente que não tinha havido um trabalho em equipa que se propusesse introduzir práticas cooperativas, para proporcionar motivação e a inclusão da criança com necessidades educativas especiais no grupo. Percebia-se que tanto a educadora titular quanto a professora de educação especial, tinham uma visão esclarecida das dificuldades do Eduardo, contudo, não se uniam para construir e pôr em prática um programa educativo direcionado ao grupo. Outro aspeto relevante são os métodos utilizados nas práticas inclusivas onde se pretende que tanto os educadores, professores e pais compreendam e reflitam sobre a necessidade das mesmas para que a criança possa evoluir no seu desenvolvimento e aprendizagem, pois são ferramentas de trabalho que, quando utilizadas de forma fundamentada, podem promover uma intervenção mais adequada. No entanto, o preparo do professor é indispensável para o uso correto das práticas adequadas a cada situação, pois a criança deve ser devidamente acompanhada para fazer aprendizagens sociais e académicas. Assim, para que haja mais inclusão nas escolas na perspetiva de Ainscow:

[...] é necessário que [os professores] assumam e valorizem os seus conhecimentos e as suas práticas, que considerem a diferença como um desafio e uma oportunidade para a criação de novas situações de aprendizagem e que sejam capazes de inventariar o que está a impedir a participação de todos (2000 apud SANCHES; TEODORO, 2006, p. 71).

Apesar das dificuldades que surgiram no caminho, o trabalho em conjunto e o uso de metodologias de intervenção adequadas contribuíram para o desenvolvimento das aprendizagens e a resolução dos problemas que existiam a nível de motivação e exclusão no grupo. Pelos resultados obtidos, pôde-se verificar que as crianças com diagnóstico de autismo podem desenvolver suas capacidades de maneira significativa e, com tratamento e acompanhamento apropriados, podem adquirir menos dependência em suas vidas, embora possam ainda subsistir dificuldades nas áreas caracteristicamente atingidas, tais como: a comunicação verbal, não-verbal e a interação social. Assim, de acordo com o grau de comprometimento, o sucesso para a socialização e outras dificuldades relacionadas ao autismo, dependerão da intensidade, adequação e proficiência do tratamento. Será fundamental para o "Eduardo" uma continuidade interventiva pedagógica, adequada à sua problemática, para poder continuar evoluindo no seu processo de aprendizagem e inclusão. Há muitos caminhos para incluirmos crianças com diagnóstico de autismo no contexto escolar e, consequentemente, na sociedade, mas temos que acreditar nelas e 
procurarmos, enquanto educadores, buscar meios para que elas ultrapassem seus obstáculos e superem as barreiras que as isolam do "nosso mundo". Neste sentido, para que a criança com perturbações do espectro do autismo possa desenvolver padrões ditos "normais" de comportamento, adquirir conhecimento e integrar-se de maneira satisfatória para exercer sua cidadania, é fundamental, tal como já preconizava Vygotsky (1987), que a criança faça em cooperação para que seja capaz de amanhã fazer sozinha. Diante disto, pudemos constatar que as educadoras, apesar de compreenderem a importância da inclusão, colocam grandes barreiras para "em conjunto" implementarem dentro de sala de aula a utilização de práticas inclusivas. É preciso ter coragem para substituir as práticas tradicionais e inovar, experimentando novas/outras práticas que, tal como está descrito teoricamente, e nós aqui experimentámos, são práticas capazes de fazer a diferença, motivar as crianças e os educadores, saindo todos a ganhar.

\section{The ciranda inclusion: promoting development and interaction in a kindergarten group which includes a child with autism}

\section{Abstract}

This article reports a project that developed the action research methodology. It aims at promoting the inclusive education in a kindergarten group that included a child diagnosed with autism. The development of the project includes a theoretical review based on some authors on inclusive education ((SANCHES, 2005, 2012; SANCHES; TEODORO, 2006; HEWITT, 2010; LEITÃO, 2010; RODRIGUES, 2006; FONSECA, 2004), the theoretical aspects and the methods of intervention in autism (LIMA, 2012; TOLEZANI, 2010; MARQUES, 2000; PIACENTINI, 2009). The analysis of the data obtained from interview, observation and sociometry enabled the characterization of the initial situation and the plan of action. By promoting the daily and intensive contact in the group, this child has found a favorable environment for the development of skills. On the contrary, previously, the child was individually looked after, and full potential development was not obtained. The daily use of practices and intervention strategies promoting inclusion allowed the development and the socialization not only of the child diagnosed with autism, but also of all other children.

Keywords: Autism. Inclusive education. Intervention strategies. Kindergarten. Research-action.

\section{Nota}

1 Segundo Northway e Weld, "o teste sociométrico consiste em pedir a cada membro do grupo que indique as pessoas com quem gostaria de se associar em diversas situações” (1957, p. 11), ajudando-nos, assim, a avaliar a interação dentro de um grupo. 


\section{Referências}

BARDIN, L. L'analyse de contenu. Paris: PUF, 1977.

BAUWENS, J.; HOURCADE, J.; FRIEND, M. Cooperative teaching: a model for general and special education integration. Remedial and Special Education, v. 10, n. 2, p. 17-22, 1989.

ESTEVES, L. M. Visão panorâmica de investigação-ação. Porto: Porto Editora, 2008. Coleção Infância.

ESTRELA, A. Teoria e prática de observação de classes - uma estratégia de formação de professores. Lisboa: INIC, 1984.

FONSECA, V. Tendências futuras da educação inclusiva. In: STOBAUS, C.; MOSQUERA, J. (Org.). Educação especial: em direção à educação inclusiva. Porto Alegre: Edipucrs, 2004. p. 41-59.

FREIRE, P. Pedagogia da autonomia: saberes necessários à prática educativa. São Paulo: Paz e Terra, 1996.

GADOTTI, M. A escola e o professor: Paulo Freire e a paixão de ensinar. São Paulo: Publisher Brasil, 2007.

GUERRA, I. C. Pesquisa qualitativa e análise de conteúdo. Estoril: Principia, 2006.

GUILHERME, M. Multiculturalismo e educação: Carta aos professores brasileiros, segundo inspiração de Paulo Freire. In: SOPELSA, O.; TREVISOL, J. V. Currículo, diversidade e políticas públicas. Joaçaba, SC: Unoesc, 2009. p. 45-50.

HEWITT, S. Compreender o autismo - estratégias para alunos com autismo nas escolas regulares. Porto: Porto Editora, 2010. Coleção Educação e Diversidade.

LEITÃO, F. A. Valores educativos, cooperação e inclusão. Salamanca: Luso-Española, 2010.

LEITE, E.; MALPIQUE, M.; SANTOS, M. R. Trabalho de projeto. Porto: Edições Afrontamento, 1990.

LIMA, C. B. Perturbações do espectro do autismo: manual prático de intervenção. Lisboa; Porto: Grupo Lidel, 2012.

KANNER, L. Autistic disturbances of affective contact. Nervous Children, n. 2, p. 217-250, 1943. Disponível em: <https://scholar.google.pt/scholar?q=Autistic+disturbances+of+affective+contact .+Nervous+Children\&hl=pt-PT\&as_sdt=0\&as_vis=1\&oi=scholart\&sa=X\&ved=0ahUKEwjCmM WngZbOAhWDOxQKHT6CDhAQgQMIHDAA>. Acesso em: 10 set. 2012.

MARQUES, C. E. Perturbações do espectro do autismo. Ensaio de uma intervenção construtivista desenvolvimentista com mães. Coimbra: Quarteto, 2000.

MARQUES, J.; SARMENTO, T. Investigação-acção e construção da cidadania. Revista Lusófona de Educação, Lisboa, n. 9, p. 85-102, 2007.

MORGADO, J. C. Currículo e profissionalidade docente. Porto: Porto Editora, 2006.

NORTHWAY, M.; WELD, L. Testes sociométricos. Lisboa: Livros Horizonte, 1957. 
PAVAN, R. Currículo e multiculturalismo: Reflexões para a formação de educadores. Revista Lusófona de Educação, Lisboa, n. 15, p. 125-135, 2010.

PIACENTINI, P. Floortime! Por que eu uso o modelo DIR? 2009. Disponível em: <http://autismoeasnovasintervencoes.blogspot.com/2009/08/floortime.html>. Acesso em: 5 set. 2012.

RODRIGUES, D. Inclusão e educação: doze olhares sobre a educação inclusiva. São Paulo: Summus, 2006.

SANCHES, I. Compreender, agir, mudar, incluir. Da investigação - acção à educação inclusiva. Revista Lusófona de Educação, Lisboa, n. 5, p. 127-142, 2005.

Em busca de indicadores de educação inclusiva: práticas de colaboração do professor de apoio educativo com o professor da turma que "inclui" alunos considerados com necessidades educativas especiais. Revista Espaço Pedagógico, Passo Fundo, v. 19, n. 1, p. 102-120 jan./jun. 2012.

Do 'aprender para fazer' ao 'aprender fazendo': as práticas de educação inclusiva na escola. Revista Lusófona de Educação, Lisboa, n. 19, p. 135-156, 2011.

SANCHES, I.; TEODORO, A. Da integração à inclusão escolar: cruzando perspectivas e conceitos. Revista Lusófona de Educação, Lisboa, n. 8, p. 63-83, 2006.

SILVA, M. O. E. Da exclusão à inclusão: concepção e práticas. Revista Lusófona de Educação, Lisboa, n. 13, p. 135-153, 2009.

TAMANAHA, A. C.; PERISSINOTO, J.; CHIARI, B. M. Uma breve revisão histórica sobre a construção dos conceitos do autismo infantil e da síndrome de asperger. Revista da Sociedade Brasielira de Fonoaudiologia, São Paulo, v. 13, n. 3, p. 296-299, 2008.

TOLEZANI, M. Son- Rice: uma abordagem inovadora. 2010. Disponível em: <http://www.revistaautismo.com.br/edi>. Acesso em: 10 set. 2012. 